\title{
2. Masculinity Matters: Men, Gender- Based Violence and the AIDS Epidemic in Papua New Guinea
}

\author{
RICHARD EVES
}

\section{Introduction}

Gender has been a key category of enquiry into the AIDS pandemic for many years. Today, every major international authority involved in the response to AIDS recognises that a gendered approach is essential to success (UNAIDS 1999, 2000a; UNAIDS, UNFPA and UNIFEM 2004; UNAIDS and KIT 2005; UNDAW 2000; WHO 2003). Programmes to reduce gender inequalities are considered to be crucial to HIV prevention (see Carovano 1995; Gupta 1995; Jewkes, Levin and Penn-Kekana 2003, 132). So, there is a broad consensus that gender matters, but is it so clear that masculinity matters?

In 2001, the United Nations General Assembly adopted a Declaration of Commitment on HIV/AIDS which stressed that gender equality and the empowerment of women were fundamental to reducing the spread of HIV (para. 14) and that there was a dire need to challenge gender stereotypes, attitudes and inequalities (para. 47). Recognising that women and girls were disproportionately affected by HIV and AIDS, the Declaration emphasised the need to accelerate the implementation of national strategies to promote men's and women's shared responsibility to ensure safe sex (para. 59) (UNDAW 2004, 5-6).

Despite this recognition that greater equality of men and women is vital to HIV prevention, many programs worked solely with women, trying to empower them in sexual relationships (Rivers and Aggleton 1999). This was partly due to a tendency to view gender as synonymous with the feminine and the issue of gender equality as a women's problem - as a matter of helping women themselves to change their circumstances. The practice of addressing only women also developed because it was women who were disproportionately 
impacted by the epidemic. It was realised that female biological vulnerability made women more likely to be infected than men, and also that women's social and economic marginalisation increased their exposure to HIV.

At least in retrospect, this focus on women seems naïve and it left the masculine as the unquestioned status quo. Its rationale has some similarity to blaming the victim. Some argue that it 'actually served to undermine women by making them responsible for HIV risk reduction' (Campbell 1995, 197; Giffin 1998, 151; Mane and Aggleton 2001, 3). It meant that two vital factors were neglected: the part played by men and the part played by broader social circumstances in the spread of HIV (Rivers and Aggleton 1999). Of course I am not suggesting that women do not need particular attention, but that it is wrong to leave men outside the equation. Largely due to the activism of homosexuals, men have been a central focus of prevention efforts in the developed world, but this has not usually been the case in the developing world, where heterosexually driven epidemics predominate. While the focus on women is of the utmost importance, especially with the increasing feminisation of the epidemic, it is evident that a strong and constructive focus on men is required in these countries. Gender, after all, does not simply equate with women; it concerns men as well, something that is often forgotten (Dowsett et al. 1998, 305; Barker and Ricardo 2005, 1).

It is now increasingly recognised that attempts to empower women in sexual relationships are based on the highly questionable assumption that they have the power and ability to control their sexual and reproductive lives (Gupta and Weiss 1993; Rivers and Aggleton 1999; Wood and Jewkes 1997). The nature of gender roles and gender relations often mean that women have far less control over these and other aspects of their lives than men, and in particular are severely constrained in their ability to negotiate safe sex.

Broad agreement now exists that men (and boys) must be involved in prevention work if HIV transmission rates are to be reduced (Campbell 1995, 207; Mane and Aggleton 2001, 26; Rivers and Aggleton 1999). Internationally, there has been a growing body of academic literature and policy documents addressing men and HIV (Campbell 1997; Carovano 1995; Foreman 1999; Hunter 2005; Setel 1996; UNAIDS 2000b, UNAIDS 2000c, UNAIDS 2001; UNAIDS/Panos Institute 2001; UNFPA 2000; Wardlow 2007). An important starting point in this response was the 2000 and 2001 World AIDS campaigns coordinated by UNAIDS under the themes of 'Men Make a Difference' and 'I Care - Do You?' which recognised the need to involve men and boys as allies in stemming the global HIV pandemic.

One consequence of the research on men that followed these initiatives has been a more complex understanding of gender and its relationship to HIV, though much more work is needed. It is now widely recognised that it is important to examine the conceptual underpinnings of masculinity, its assorted meanings 
and values, and how and why it generates behaviours which contribute to the spread of the virus. Particularly pertinent here is the relationship between masculinity and gender-based violence, which is receiving increased interest internationally (see Campbell 1992; Barker and Ricardo 2005; Medrado 2003; Walsh and Mitchell 2006).

Gender-based violence is any form of violence used to define or keep in place strict gender roles and unequal relationships (UNDAW 2004, 31). Thus, it constitutes a 'policing mechanism' to 'keep women (or different types of men) in their place', to assert 'who makes the decisions' in a relationship or 'who holds the power' (UNDAW 2004, 31; and see UNFPA, UNIFEM and OSAGI 2005; UN 2006). Though it generally refers to men's violence towards women and girls, it also refers to violence toward other men and boys who are considered to challenge prevailing masculine gender ideologies. Importantly, making distinct the gender dimension helps to firmly ground the concept in gender and directs attention to the cultural dimensions of gender and the way children are socialised to become adults. Especially, it highlights the ways that masculine socialisation often authorises violence against women.

Until recently, male violence towards women was largely taken to be a separate problem from HIV, but now that such violence is known to play a prominent role in the spread of HIV, they are usually treated as dual and interconnected epidemics which should be addressed in an integrated way (Global Coalition on Women and AIDS and WHO 2004; Nduwimana 2004; Maman et al. 2000; Jewkes et al. 2003; Rothenberg and Paskey 1995; WHO 2001, 2004). ${ }^{1}$

The topic of this chapter is the constructions of masculinity which affect the perpetuation of gender-based violence and the spread of HIV, in particular in Papua New Guinea (PNG). I begin by examining from this angle the government response to the epidemic in PNG. I then outline the theory of the cultural construction of masculinity and describe the cultural influences that contribute to the dominant form of masculinity in that country. Next, I describe the extent of violence against women in PNG and explain how gender relations legitimate this. The extent to which the cultural constructions of gender which give men power limit women's ability to engage in safe sex is an important theme that follows. Next, I analyse and critique attempts that have been made to address the issue of gender-based violence through prevention messages which seek to

\footnotetext{
1 The issue of violence against women has for some time regularly been on the agendas of international forums, and international legal and policy frameworks for addressing it have been developed. Landmark achievements to this end include the UN Declaration on the Elimination of Violence Against Women (1993), the Dakar Platform for Action (1994), the Beijing Platform for Action (1995) and UN Resolution 1325 on Women Peace and Security (2000). Violence against women was identified as one of the twelve critical areas of action in the Beijing Platform for Action, and at the eleventh session of the Convention on the Elimination of All Forms of Discrimination against Women (CEDAW) (1992), General Recommendation No. 19 was formulated especially to address the issue.
} 
re-define masculinity. I conclude by suggesting more considered approaches that are more likely to be successful in reducing gender-based violence and HIV transmission.

\section{Engendering a Response to HIV}

Cultural constructions of gender have a major impact on the way the epidemic is unfolding in PNG (Eves and Butt 2008; Haley 2008, 33; Beer 2008, 105), but there has been very little appreciation of this by those at the forefront of the national response. Overall, recognition of gender and the need to examine it in the context of gender-based violence and HIV transmission has been slow and largely donor-driven.

The response to the epidemic in PNG is currently guided by the National Strategic Plan (NSP) 2006-2010, which barely acknowledges the gendered nature of the epidemic (PNG NAC 2006a). A UNDP gender audit of the plan notes that it does not identify gender as one of its several focal areas nor as one of its cross-cutting themes to be addressed through the other focal areas (UNDP 2005, 8). Its recognition of gender is limited mainly to a rather brief discussion in the context of national vulnerability. It acknowledges to some extent gender inequality and the low status of women, referring to their much lower levels of literacy than men, limited employment opportunities, heavy health burden and very limited representation at all levels of the economy and government (UNDP 2005, 7). However, it fails to take seriously the need to assess the differential impact of the epidemic on men and women infected or affected by the epidemic (UNDP 2005, 8). The plan pays scant attention to the widely recognised connections between men, violence and HIV. While it acknowledges the violence men use against women to maintain their authority and the high incidence of sexual assault including rape (PNG NAC 2006a, 10), which exposes women to HIV, it sees gender in terms of women's vulnerability. This is a lopsided definition of gender which includes women as a category but not men.

The UNDP gender audit found 'only a rudimentary level of understanding of gender on the part of a majority of stakeholders and most certainly only very basic level of knowledge of how gender intersects with the epidemic and what might be its relevance for strategies and activities identified in the NSP' (2005, 27). Even more disturbing was the claim by some of the stakeholders interviewed during the audit research that there were 'no gender issues in PNG's HIV epidemic' (UNDP 2005, 27). The higher levels of infection of female teenagers was put down to promiscuity and the 'greed for quick money' (UNDP 2005, 27). 
The tendency among some, mostly male, stakeholders was to attribute blame to girls rather than to relate it to the economic and social susceptibility of girls to sexual advances by older men (see Luker with Monsell-Davis this volume).

Attempts have been made to rectify the inadequate focus of the NSP by developing a specific gender policy and plan, the National Gender Policy and Plan on HIV and AIDS 2006-2010, as a complement to the NSP (PNG NAC 2006b). This significantly advances the plan's gender policy component by clearly acknowledging that 'the biggest single factor affecting a person's risk of contracting HIV, and the consequences of infection, is gender' (PNG NAC 2006b, vi). However, there still appears to be very little developed action in this regard. For example, the PNG report to the United Nations General Assembly Special Session in 2008 comments that while a gender policy has been launched, 'there is a common misunderstanding in PNG that gender refers to women and girls. Few programs address gender roles and relations, gender power configurations, masculinity, male aggression and gender-based violence, sexual coercion and rape, and trans-generation sex' (PNG NACS and Partners 2008, 65).

\section{Masculinity and the Making of Men}

Theoretical understandings of masculinity have moved beyond taken-forgranted and universal conceptions of 'men' across cultures, regardless of histories and contexts. More considered historical and cultural study reveals that the nature of masculinity is fluid, depending on its setting, which is everywhere constantly reshaped by new influences. Indeed, within any society multiple forms of masculinity co-exist, reflecting different factors and different groups. That particular forms of masculinity are culturally elevated above others at various times and places, is another indication that considerable variation exists (Cleaver 2002, 7).

With the development of theory, new concepts and terms have been needed to point to and differentiate the various forms of masculinity. Recent writings on masculinity argue that within any one society there are ways of being a man that are dominant and considered exemplary, while others are seen as less than ideal. The former are termed 'hegemonic masculinities', while the latter are 'subordinate variants' (Cornwall and Lindisfarne 1994, 3; Connell 1995). Hegemonic masculinities exert pressure on men to behave in particular culturally and socially sanctioned ways. They legitimise and enforce the roles not only of women but also of men, 'constraining what they can and cannot think and do ... [They] for example, have an important role to play in policing the boundaries of heterosexuality' (Mane and Aggleton 2001, 29; see also Brown, Sorrell and Raffaelli 2005, 586; Courtenay 2000; Larkin, Andrews and Mitchell 2006, 217). 
The rituals associated with the transition from childhood to adulthood have been a major focus of anthropological studies of masculinity in PNG (Herdt 1981, 1992). These rituals confirm the point that gender, in this case masculinity, is cultivated through ritual and other cultural means. So far, however, insufficient effort has been made to understand the broad significance of masculinity and especially the rise of plural, and often competing masculinities, that have come about as a result of social and cultural change (but see Brison 1995; Eves 2006; Wilde 2003). Many changes that have had a profound impact on gender have occurred, such as Christianisation, Western education, exposure to modern media and labour migration. Significantly, some of these changes have seen the emergence of new forms of masculinity, such as those based on Christianity, which often eschew violence against women. On the other hand, these changes have sometimes brought the reinscription of 'traditional' conceptions of masculinity, which legitimate new forms of power in the contemporary context.

Generally, people in PNG are valued for their achievements. Although this applies both to men and women, the general rule is that women serve to assist a man to achieve renown. Women are valued for their role of raising children and producing the kinds of wealth (such as pigs, garden produce and artefacts) that are exchanged during the ceremonies and presentations where men gain political power and prestige. Women have an important role in maintaining social relations between groups, since the exchanges on which men build their prestige depend on the kinship relationships gained through marriage (Brown $1988,125)$. It remains true that 'in the final analysis, the idea which men hold of themselves is based on what men do rather than what they have at birth' (Read 1982, 70). Men must try to prove themselves economically, socially and politically, which usually requires self-assertion and public accomplishment in the form of oratory, conspicuous displays of wealth, political office or other public status. The 'big man', who has achieved renown, is respected, while the man who has not, is contemptuously labelled rabisman (rubbish man). This renown depends on a man's ability to cultivate and harness pre-existing kinship and social relationships, rather than being 'self-made'.

The chief characteristics that make up the dominant, exemplary form of masculinity are assertiveness and powerfulness. Traditionally, the masculine ideal is 'a strong warrior and orator, a "big man" directing and leading a group of men in warfare and ceremony' (Brown 1988, 128). Though men may no longer be socialised to become warriors, they are still socialised to be extremely assertive, to the point of aggressiveness (McDowell 1990, 174). Consequently, anger and violent redress are considered natural and appropriate responses to insult or challenge. There is a general inclination to avenge perceived or actual insults, since these are perceived as injuries to one's person that need to be reciprocated. Anger is sometimes valued because it enables things to be done 
that could not normally be done. For example, in some places it is regarded as a motivating and energizing force, which has made possible men's great acts of warfare (Nash 1990, 138). ${ }^{2}$

\section{Engendering Violence}

Because of their desire to raise successful sons who will be big men who control and dominate over others, PNG boys are frequently socialised from early childhood to interact assertively and aggressively with others. This was also often a feature of male initiation rituals in parts of PNG (Herdt 1982). These 'rituals of manhood', as they have been called, involved the radical separation of boys from any contact with women and fostered male sociality and bonding. Though it is unclear whether these rituals continue to be practised, the belief continues to be strongly held that women, especially their bodily secretions, are dangerous and undermine men's power. In contexts such as hunting, preparation for dances and warfare, avoidance of women is considered essential to success. In circumstances where young men and boys are socialised to believe that women are antithetical, it is perhaps hardly surprising that violence against women is taken for granted as acceptable.

Currently, as McLeod observes, women in PNG enjoy neither freedom of movement nor equal protection by the law $(2005,115)$. Many women live under the threat of violence and this restricts their ability to move freely in the community, to use public transport, to access health and education services, and to travel to market or to the workplace (AI 2006, 1; NRI and JAG 2005,6). Women are ill-served at all levels of the male-dominated law and justice sector, ranging from the village court system to the police, where cultural assumptions about male superiority are commonly embraced, and issues that affect women, such as sexual and domestic violence, are either ignored totally or not seriously pursued. Village courts also demonstrate 'excess traditionalism', espousing a timeless and strongly masculine concept of tradition (McLeod 2005, 115). ${ }^{3}$ Moreover, the threat of violence from intimate partners and husbands means women are often unable to earn an income, or if they do, to control its use, rendering them financially dependent. Neither, as I show below, do women have control over their bodies and their sexual and reproductive health, very often being unable to determine whether, when and with whom they have sex and whether or not they become pregnant.

2 In the past, a man could be turned into an angry killer, a pikonara, with great strength through the ingestion of a magical powder, which included human bones. Any boy child showing unusual belligerence was believed likely to grow up to be a pikonara (Nash 1990, 135).

3 In some contexts, though, women are very successful users of village courts (Goddard 2004). 
The Papua New Guinea Constitution has a stated commitment to equal human rights, and PNG is a signatory to the Convention on the Elimination of All Forms of Discrimination against Women (CEDAW). ${ }^{4} \mathrm{PNG}$ is also a signatory to other relevant international and regional platforms for action committing the government to promoting the advancement of women by eliminating family and sexual violence. ${ }^{5}$ However, like many other countries, PNG has not matched this international level of progress by developing policies at the national level. The good work done by the Law Reform Commission (LRC) in the 1980s and 1990s, in formulating appropriate recommendations for legislative reforms and for broader action to address violence against women in PNG, was largely ignored by politicians. ${ }^{6}$ This failure, and many others since, has led Amnesty International to conclude recently that the PNG state 'is doing very little to promote and fulfil the realisation of women's rights or to protect women from human rights abuses. In fact, State agents themselves are often directly implicated in perpetrating violence against women' (AI 2006, 3; HRW 2005, 2006; Eves and Butt 2008, 19). Numerous reports on the issue of gender-based violence in PNG have appeared over the years (AI 2006; Bradley 2001; HRW 2005, 2006; INA 2001; LRC 1992). ${ }^{7}$

The full extent of the problem of gender-based violence in PNG today is difficult to gauge, because no nation-wide generalisable research has been undertaken since the Law Reform Commission's research in the 1980s. This found widespread violence against women in the form of wife-beating, 67 percent of women in rural areas and 56 percent of women in urban areas having been abused by their husbands (Bradley 2001, 7). It also found considerable regional variation, ranging from a maximum of 100 percent in the Western Highlands Province to a minimum of 49 percent in Oro Province. For urban-dwellers, it showed that 56 percent of wives of low income earners and 62 percent of elite wives had been physically assaulted by their husbands (LRC 1987, 2).

In the absence of recent comprehensive data, statistics from the police, reports in the media, and anecdotal evidence show that gender-based violence, and especially violence against women, is still widespread and in epidemic proportions. Week after week, horrific reports appear in the national media of

4 PNG ratified the convention in January 12, 1995. So far, PNG has not submitted reports as required of signatories. For a more detailed account of PNG's commitments, see Bradley $(2001,4-5)$ and Amnesty International $(2006,25-6)$.

5 Including the Pacific Platform for Action on Women and Sustainable Development, 1994, and the Revised Pacific Platform for Action on the Advancement of Women and Gender Equality, 2004.

6 For more detail, see Amnesty International (2006, 26-7). Some legislative reforms have been introduced by Lady Carol Kidu, though the majority of the LRC recommendations are yet to be implemented (AI 2006, 27).

7 These reports make suggestions about what the state should be doing through legislative reform and the law and justice sector, and about support mechanisms the state should provide for the victims of violence. None of these, however, focuses on the issue of masculinity or recognises the need to work closely with men and boys in addressing the problem. 
women being killed by intimate partners or of cases of violent rape. Other forms of violent crime also appear to be at epidemic proportions and this may indicate the emergence of a new masculine ethos, the origins of which have hardly been investigated.

Research in 2005, as part of the PNG Armed Violence Assessment in the National Capital District (NCD) and the Southern Highlands Province (SHP), also confirms that a significant proportion of the violence in communities in PNG occurs in households among intimates and kin. Evidence from household surveys suggests that serious domestic violence is rising and that this is a primary contributor to feelings of insecurity, though other factors such as social conflict and armed criminality are also considered important (Haley 2005, 30; Haley and Muggah 2006, 166). The researchers found that in the six months prior to the survey, domestic and family violence affected 18 percent of surveyed households in the NCD and 26 percent in the SHP. Moreover, they indicate considerable underreporting, since the respondents made it clear that they reported only the more serious cases, such as those involving broken limbs (Haley 2005, 30; Haley and Muggah 2006, 170-172). Significantly, they also found that domestic violence was not evenly represented in all areas of the NCD, with a greater number of cases occurring in the settlements. They also found a correlation between the provincial origins of NCD households and the preponderance of domestic violence. For example, domestic violence marked 24 percent of the households originally from the Highlands or Gulf Provinces and 23 percent of those from Central Province, while those households with origins in the Momase and Islands regions reported no domestic violence (Haley and Muggah 2006, 172).

Sexual violence is a major problem in much of PNG and has been for many years (NSRRT and Jenkins 1994; Bradley 2001, 13; Banks 2000). Violence and coercion, including verbal threats and forced sex, are common features of young people's sexual experiences and of adult intimate relationships. The Interim report of the Law Reform Commission reported that of the rapes and sexual assaults reported to Port Moresby General Hospital for the first three months of 1985, 22 percent were of girls aged between 11 and 15 years old, 12 percent of girls between eight and 11 years old, and 13 percent of girls under eight years old $(1987,6)$. In the research conducted by the NSRRT and Jenkins, 60 percent of men reported having participated in a gang rape (known as line-ups), at some time in their lives, involving an average of ten men at a time $(1994,102)$.

More recently, the Port Moresby Community Crime Survey found in 2004 that females were most likely to suffer sexual assault, followed by property crime with force and vehicle theft (NRI and JAG 2005, 3). The Port Moresby Diagnosis of Insecurity Report also reports high levels of sexual violence. In a summary of the criminal activities of 1,097 male youths, it reports 74 had committed 
rape (UN Habitat 2004, 24). ${ }^{8}$ Although not disaggregated by sex, this research reports 22 percent of the youth sample had been a victim of physical abuse and 16 percent of sexual abuse (UN Habitat 2004, 24).

As with domestic violence, accurate and up-to-date figures on the extent of sexual violence in PNG are hard to come by, although the PNG Armed Violence Assessment confirms that it remains a major concern. In the six months prior to the survey, over 8 percent of the respondents in the SHP and 3 percent of respondents in the NCD reported that someone in their household had been the victim of sexual assault or rape, often involving the use of weapons, such as firearms and bush knives (Haley 2005, 35; Haley and Muggah 2006, 170, 174). In the SHP, 89 percent of the incidents occurred in the Hela region (the western end of the province), while in the NCD 60 percent occurred in the settlements (Haley 2005, 35). In rural PNG, most sexual assaults and rapes occurred in the village, often in the home, and the perpetrators were generally known to the victim (Haley and Muggah 2006, 174). They also found that young and very young girls make up a greater percentage of rape victims than occurred two decades ago (Haley and Muggah 2006, 174).

These findings are generally supported by Lewis and colleagues, who found high levels of sexual abuse among respondents in their survey undertaken in 2005 and 2006 among 415 women, mostly between 20 to 30 years of age, attending antenatal, STI and VCT clinics in four provinces. ${ }^{9}$ They found that 27.5 percent (114 of 415) of women had been sexually abused under the age of 16 years (Lewis et al. 2007, 5, 57). The abuse women were subjected to included unwanted sexual talk (18.5 percent or 77 women); unwanted sexual touching (13 percent or 54 women); sexual penetration (10 percent or 40 women) and sexual exposure by the offender (1 percent or 4 women) (Lewis et al. 2007, 57). Those subject to sexual assault included some who were gang-raped. As other research has also shown, the offenders were mostly known to the victims, being relatives or neighbours (Lewis et al. 2007, 5).

The ramifications of this kind of experience for these women are major. Those who were subject to sexual abuse were more likely: to be in relationships that were violent (70 percent compared to 54 percent) and sexually abusive (65.5 percent compared to 38 percent); to have sex at a much younger age (16.9 years compared to 18.24); to work away from home (37 percent as opposed to 21 percent); to be involved in the exchange of sex for money (29 percent as opposed to 2.7 percent), goods or gifts (18.6 percent compared to 2.7 percent) or favours (21 percent compared to 3 percent); to have more sexual partners (16.7 percent compared to 5.9 percent having two current partners); to participate in

8 Also 31 murders, 130 assaults, 136 car-jackings and 59 cases of unspecified violence (UN Habitat 2004, 24).

9 National Capital District, Western Highlands Province, Morobe Province and Western Province. 
casual sex (25 percent compared to 10 percent) than those who were not subject to sexual abuse. Women who have been abused as children are more likely to be HIV positive, with 28 percent of women who were abused being HIV positive (Lewis et al. 2007, 5, 57).

\section{Legitimating Violence}

Violence is seen as legitimate only if the woman is perceived to have failed to behave in the manner proper to a wife. As one man remarked to me, 'We don't fight for nothing, there must be a reason' (mipela no pait nating nating, i mas got as). Women are also generally in agreement with this view; as one woman said, 'Husbands don't hit their wives for no reason' (man i no paitim meri nating). Thus it seems that though violence is condoned, unprovoked violence is not.

Unquestionably, the prevailing gender ideology in PNG is that violence is an entirely appropriate corrective to even the slightest failure of wives to fulfil their perceived marital duties and proprieties. The research by the Law Reform Commission found that the wife's failure to carry out her duties was stated by 63.2 percent of men as leading to problems in marriage (this was followed by sexual jealousy at 62.1 percent) (Toft and Bonnell 1985, 20, 45, 46). ${ }^{10}$ According to the literature, this belief remains widespread in PNG. For example, it underlies Tolai domestic violence: 'The general rationalisation for coercive violence against wives is that it is "corrective", "educational", "informative", or "for teaching a lesson"" (Bradley 1985, 50). It exists also among the Abelam of East Sepik Province, where the men believe that "occasional beatings are sometimes "necessary" in order to socialise women properly' (Scaglion 1990, 189). Among the Bun, also in East Sepik Province, the reason men gave for hitting their wives was that the wife did not prepare food or did not carry out her work (McDowell 1990, 180). Similarly, the Kewa of the Southern Highlands say that a husband hits his wife when she disobeys him or fails to do his bidding (Josephides 1985, 94).

By far the commonest 'mistake' I found during fieldwork in Chimbu was for a wife to refuse her husband sex. One woman, a member of an interdenominational women's group who often counsels women who have experienced domestic violence, suggested that regardless of what men may say in public about the causes of violence, the main one from her experience was women refusing their husbands sex. She went so far as to say that there wasn't a night that went by when such violence, often including marital rape, did not occur.

10 Female respondents gave less priority to the wife's failure to meet obligations (36.4 percent) and more to sexual jealousy (69.4 percent) (Toft and Bonnell 1985, 20). 
This has also been found by research in other parts of PNG. Lewis and colleagues found that 52.2 percent ( 217 of 415 ) of women felt that they could not refuse sex to their partners (2007, 118; see also Pantumari and Bamne this volume). This lack of control over sex was even greater in relationships marked by physical violence and 71 percent of women who said they were subject to this kind of violence could not refuse sex (Lewis et al. 2007, 118). Women who were sexually abused were also in a similar situation, with 72 percent of sexually abused women unable to say no to sex with their partners. There were also high figures for emotional abuse and women who were socially isolated by their husbands or partners, with 51 percent of emotionally abused women, and 71 percent of women socially isolated, being unable to refuse sex (Lewis et al. 2007, 6). Refusing sex was the biggest trigger for violence in the relationships with 176 women of 415 (Lewis et al. 2007,6).

Far from being simply impetuous and irrational, the violence that men inflict on women is an execution of power which has the effect of keeping women in their place, subservient to men. Women's subordination is most clearly marked in the marriage relationship, since a woman is bound to obey her husband by virtue of the bride-price that has been transferred to her relatives from her husband's relatives (Bradley 1985, 34). Thus the payment of bride-price is used to justify the husband's authority over his wife, entitling him to her labour, her sexual services, and her full obedience. Put bluntly, the underlying and general objection is to any exercise of agency on the part of a woman. ${ }^{11}$ What is at issue, then, are the traditional relations of power and the continuation of the control that men have held over women. This has the logical consequence of legitimating violence, since having authority means exercising authority and, ultimately, using punitive means to enforce this.

Tok Pisin expressions, such as baim meri (buying a woman) fail to convey the complexity of the exchange relationship and have the effect of reinforcing the belief that the woman now becomes the property of the man. It appears that under various modern influences, perhaps especially the commodification of exchange, the traditional meaning and practice of bride-price has been eroded and largely forgotten, a simplified version taking its place. Rather than being seen as an exchange which creates a relationship between two social groupings, and the bride's kin being compensated for her loss, the bride-price exchange is now widely understood quite literally as a simple property transaction, in

\footnotetext{
11 It should be stressed that women are not always passive victims of male domination and violence, but in many instances are agents who develop strategies and responses to the situations they find themselves in (see Wardlow 2004, 2006). Unfortunately, the agency women express is often reactive, being defined by the parameters of the masculine culture in which they live. The domestic violence that takes place in polygynous households, for example, often sees wives fighting between themselves.
} 
which a woman becomes the property of a man. This is expressed by women, for example as: em baimim mi pinis (he's bought me), em ownim mi (he owns me), or mi properti bilong en (I'm his property).

Having 'purchased' a woman, a man believes he owns her, as though she is little more than an object. This was put by one woman in the following way: 'He feels he has paid bride price and he owns me. I can't do anything else. I have to sleep with him' (Lewis et al. 2007, 121). As Zimmer-Tamakoshi remarks, men have variously portrayed women as men's 'hands', 'tradestores', 'tractors' and 'capital assets' $(1997,541)$. Such dehumanising designations point to women's roles as labourers and assets for the creation of wealth. During field research in Chimbu Province, one woman explained it this way: 'When a man has exchanged bride-price (baim em), he is the boss now. So he claims her as his property, or something like that, and the woman will be his labourer until he dies'.

However, it is important to note that violence against women is by no means confined to wedlock and that many cases of physical abuse occur in relationships where bride-price has not been exchanged (see Toft 1985). While many of the rationales for men's power and control over women are given added weight by marriage, to understand marital violence, 'it is essential to see it in the context of relations between men and women in general, and between husbands and wives in particular' (Bradley 1985, 33). Violence against women is legitimated not only by the exchange of bride-price but also by men's general domination over women. ${ }^{12}$

The normalisation of violence that is generally a cultural feature of PNG society has specific implications for HIV transmission rates. Jenkins has stressed that gang-rape or lainap results in a very high rate of HIV transmission; recent work has also highlighted the sexual abuse of very young girls and children as a cause of HIV transmission (HRW 2005; HELP 2005; Luluaki 2003); however sexual violence - as discussed below - is a standard feature of marriage. Even where certain forms of violence against women are not directly related to HIV transmission, as directly as say sexual violence, it underpins the severely diminished sexual agency that women possess (see Scheper-Hughes 1994, 993; Liguori and Lamas 2003). With so little control over their lives and their bodies, they are extremely vulnerable to infection.

12 Some commentators have suggested that male angst and confusion in the face of rapid change have led to violence against women. Josephides, speaking of the Kewa of the Southern Highlands, refines this view, saying that these changes are giving rise to a comparative lessening of male power in relation to women which sees women slipping from men's grasp $(1994,187)$. The changes, such as the Constitutional recognition of rights of equality, the availability of education and new career opportunities, that have brought a new independence to women, disturb the traditional gender roles. Much violence against women is motivated by fear because of the resultant weakening of men's ability to control them (Josephides 1994, 190). 


\section{Negotiating Safe Sex: Is It as Easy as ABC?}

PNG's intervention to stem the epidemic has been based on the ABC (A for abstinence, B for be faithful, and C for condoms) model of prevention, which is widely employed in many countries (Eves and Butt 2008, 6, 19; Wardlow 2008, 203-204). ${ }^{13}$ Such recommendations are gender-blind since they assume a subject who is in a position to control his or her body and sexual health, oblivious to the fact that while this may sometimes be the case for men, it is rarely so for women. Failing to recognise that sexual encounters are arenas in which the unequal power relations between men and women are played out, they assume that the agent of prevention is an independent person who can make decisions irrespective of the opinions and actions of others and of the wider social context in which they live (Wood and Jewkes 1997, 43-44; see Ellison, Parker and Campbell 2003, 5).

Exhortations to practise safe sex raise the perplexing question of how this might be achieved in the context of unequal power relationships, where social and economic conditions severely limit women's ability to control their sexual activity. ${ }^{14}$ Further, these HIV prevention messages promote the myth that being faithful in marriage makes one immune from HIV, leading people to disregard potential risks (Bujra 2000, 72). A great deal of research is suggesting that far from being immune to HIV infection, married women are more susceptible because their husbands often do not follow the injunctions of the ABC. Women are often not aware of the past or even the present sexual history of their husbands and so do not perceive themselves as potentially at risk of HIV infection. Even when they are aware of their husband's other sexual relationships, they often can do little (cf. Pantumari and Bamne this volume; McLeod and Macintyre this volume). This has led some commentators to remark that marriage is a high-risk setting. In PNG there exist many instances of women who have practised marital fidelity being infected by their husbands (Aeno 2005; Hammar this volume). As noted above, sex is seen by husbands as their prerogative to which 'no' is never an acceptable answer, and as I describe below, it is a brave woman who asks her husband to use a condom.

In the context of unequal power, it is invariably men who determine the timing of sexual intercourse and its nature, including whether a woman should try to conceive, and whether or not condoms will be used (Eves and Butt 2008, 9; Campbell 1995, 197; Gupta and Weiss, 1993; WHO 2001, 11; Wood and Jewkes 1997, 41; Wood, Marforah and Jewkes 1998, 235). Evidence from around

13 More recently, this has been expanded by the addition of a D, signifying 'do other things (than penetrative sex)' (PNG NAC 2006b, iii, 5).

14 As Seidel and Vidal noted some time ago, married women are not even regarded as being at risk in some national intervention programs, suggesting 'a glaringly inadequate construction of sexuality' $(1997,64)$. 
the world suggests that conditions where women have little power and men exercise control in intimate relationships are associated with increased HIV risk behaviours and infection (Dunkle et al. 2004; Chege 2005, 115). As Maman and colleagues suggest, 'as long as traditional gender norms for sexual relationships persist, defined by men pressuring women and women resisting, negotiation of condom use by women remains difficult' (2000, 473; Jewkes, Levin and PennKekana 2003, 126).

Violence, of course, intensifies the problematic nature of existing HIV prevention strategies that are promoted globally (Maman et al. 2000, 461). ${ }^{15}$ Violence or the ever-present threat of violence severely constrains women's ability to adopt safe sex practices, women who live in abusive relationships being unable to negotiate condom use or even to suggest using them (Eves and Butt 2008, 19; Campbell 1995, 197; Chege 2005; Johnson 2001, 126; Larkin, Andrews and Mitchell 2006, 209; UNFPA, UNIFEM and OSAGI 2005, 18). HIV prevention programs will have limited impact unless they somehow take into account the role of violence in women's lives (Maman et al. 2000, 476).

The study by Lewis and colleagues found that women in PNG are also limited in their ability to negotiate condom use due to lack of knowledge and experience, which are generally seen as men's business, and due to misinformation about the effectiveness of condoms. This study found that women who attempt to negotiate condom use are likely to experience anger and physical violence from their husbands or partners (Lewis et al. 2007, 9, 139-40). Asking their sexual partner to use condoms was one of the three most common triggers for men to use violence. As one woman remarked: 'If I tell him to use condom he will bash me up, he says I am his wife and don't need condom' (Lewis et al. 2007, 109). Even women who assessed their own risk of being infected with HIV as high, because of their partners' other sexual relationships, were unable to use condoms. For example, 64 percent who see themselves as 'at risk' do not use condoms (Lewis et al. 2007, 6).

Much international research has shown that while women are willing to use condoms with their non-regular partners, they are less likely to do so with their regular partners (Heise and Elias 1995, 936, 938). In the United States, for example, condom use is much more likely in fully commercial sex than it is in longer-term or more intimate relationships, and it is almost unknown in marriage (Maman et al. 2000, 473). This also appears to be the case in PNG where women use condoms at a higher rate when exchanging sex for gifts, goods or money (Lewis et al. 2007, 131). Condom use is more likely if the woman experienced some form of childhood sexual abuse. Forty percent of women who

15 Research in South Africa has found that more frequent condom use was associated with lower levels of violence for women in their primary relationships (Harrison et al. 2006, 716). 
were sexually abused as children say that they use condoms with their partners compared to 24 percent of non-sexually abused women (Lewis et al. 2007, 134). The reasons for this correlation are unclear and research to investigate why and how this is so may be worthwhile.

As in many parts of the world, efforts to promote the use of the male condom have failed to reduce HIV rates in PNG. As elsewhere, this is largely because of men's resistance to behavioural change and especially their reluctance to use condoms. PNG men prefer sex which is 'skin to skin' as it is sometimes called (see Lewis et al. 2007, 139). More generally, there is a widespread perception in PNG that the distribution of condoms has licensed pre-marital sex and sex outside of marriage and that condoms are associated with sex-work. Far from containing sexuality and confining it to marriage, condoms are viewed as unleashing it and, as a consequence, spreading HIV (see also Lewis et al. 2007, 137; Wilde 2007, 62 and below).

The research by Lewis and colleagues found that while there was more condom use by women today than in some figures cited in the literature (see for example UNDP 2005, 7), it was still not very high or regular (2007). Out of the 409 women who answered the question 'Do you use a condom with your partner?' 73 percent (299) said they did not. Of those who did use them, 19 percent (76) used them sometimes, 6 percent (23) used them often and 3 percent (11) used them always. Significantly, and of concern, is that 63 percent who were HIV positive reported that they do not use condoms (Lewis et al. 2007, 129-30).

Recent research among men has found that men's use of condoms is higher but also not very regular and is accompanied by the same kinds of concerns and misinformation that Lewis and her colleagues found. ${ }^{16}$ A survey undertaken by Wilde, in 2004, on condom use in Western Province, found that many respondents were concerned that condoms were not 100 percent effective, with more than 30 percent believing that even when they were used properly they would not prevent the transmission of HIV (Wilde 2007, 64). Despite this, many men believed nevertheless that condoms were effective for family planning and could prevent pregnancy. This appears to be a widely held belief, and I came across a similar idea during fieldwork in the Southern Highlands Province in 2007.

16 In the last three years, 91 of the total surveyed said they were sexually active, with 22 of the 71 married men admitting they had extramarital affairs and of these 13 saying they did not use a condom. A total of 26 men who had one or more sexual relationships said condoms were not used (Wilde 2007, 64). 


\section{Redefining Masculinity and the Language of Prevention}

In recognition of the extent to which masculine attitudes and standards prevent them from practising safe sex, efforts to understand and target these have begun to increase. In PNG in recent years, some attempts have been made to put out prevention messages targeting the general issue of violence against women and the more specific issue of violence and HIV. A number of these interventions have endeavoured specifically to convert masculinities founded on violence to those that embrace a respect for women as well as the practice of safe sex. Here I review some of these initiatives, focussing initially on interventions targeting violence against women, before discussing those that address violence and HIV.

Internationally, campaigns against violence have tried to promote non-violence as a desirable masculine trait. As Flood writes, anti-violence campaigns directed at men have adopted three broad strategies. The first of these is to promote alternative constructions of masculinity which displace the positive cultural association between violence and masculinity. This has meant appropriating the cultural expectations of manhood to give non-violence a masculine face. He refers to this as a 'rescripting' of masculinity. An example was the production of the slogan, 'Real men don't bash or rape women', used internationally including in PNG. The second strategy draws on stereotypically masculine culture, particularly sport, to appeal to men. The slogan, 'Violence Against Women-It's against the rules', used in an anti-violence campaign in New South Wales is one instance. The third strategy has been to show men speaking out, or standing together, against violence. Such campaigns have sometimes used men who have a public profile, such as celebrities or sporting figures, whose opposition to violence, it is hoped, will be emulated (Flood 2002-3, 28). Other campaigns have sought to appeal to ordinary men by utilising unknown men who have no public profile, but with whom men are likely to identify because of their ordinariness.

In PNG, campaigns addressing violence against women have followed some of the strategies Flood identifies. Some simply employ declarative statements, mirroring the slogan used internationally: 'Stop Violence against Women'. For example, a t-shirt produced by National AIDS Council Secretariat (NACS) has a red hand on a yellow background with the statement 'Stop the Violence Against Women'. The international NGO, Save the Children, has produced two posters that involve the kind of 'rescripting' of masculinity that reinforces gender difference. These feature a married couple on one, and young couple on the other, with the couples in intimate proximity. Both carry the main message of Bel isi imas stap oltaim, which translates as an imperative: 'Always be calm and coolheaded'. The poster with a married couple is about wife-beating, with man 
saying that when he and his wife have a disagreement they sit down and sort it out (Taim mitupela igat bel hevi, mitupela $i$ save sindaun isi na stretim). He adds, 'I'm a real man, I don't beat women' (Mi trupela man, mi no save paitim meri). ${ }^{17}$ The second poster with the young couple addresses the issue of non-consensual sex or rape, with the man saying, 'If she says no, I say that's alright, we're together on that' (Taim en tok nogat mi tok em orait, wanbel $i$ stap). This poster also redefines what constitutes a real man by declaring, 'I'm a real man, I don't ruin (rape) women' (Mi trupela man, mi no save bagarapim meri). ${ }^{18}$

Organisations such as AusAID, the Australian government aid organisation, are increasingly using sport as means to promote important health and social messages. This sporting diplomacy has involved sponsoring matches between Papua New Guinea and Australia and visits by high-profile sporting figures from Australia to communities to discuss issues such as HIV and violence against women. The game of rugby league, which is hugely popular throughout PNG, has been at the forefront of this sporting diplomacy and in March 2008 the Prime Minister of Australia announced a $\$ 260,000$ package of support to develop sport, with a significant proportion being assigned to rugby league (Australian Government 2008).

Rugby league, the only sport in PNG to run a full national competition, is considered the national sport and is often put forward as a medium for national unity, a way of uniting the diverse cultures of the PNG nation. Perhaps incongruously, Australian rugby league is followed fanatically by tens of thousands of PNG fans. Even in the remotest villages one can come across men wearing Australian Rugby League jerseys and people knowing the names of ARL teams and players. The annual series of three 'State of Origin' rugby league matches between the teams of the Australian states of Queensland (who wear the colour maroon) and New South Wales (who wear the colour blue) are major events in PNG. Everyone tries hard to get to the nearest town or city in the hope of viewing the match on television. Fans paint their faces and don the colours of their respective teams, PMVs (Public Motor Vehicles) are decorated with flags and other paraphernalia, and supermarkets sell boxes of sugary breakfast cereals in blue and maroon and saveloys and matching buns in either blue or maroon colours!

17 The website of The National newspaper used a similar slogan on its Weekender page during 2006. In this case, the message, 'Real men don't hit women' was superimposed on a photo of a young woman with a thick bandage on her right eye and her arm in a sling. The newspaper had used the same photograph previously on a poster distributed with the printed edition, but bearing the words, 'This could be your sister ... wife bashing is wrong!' On seeing this poster, a senior police officer at a meeting with others working in the Law and Justice sector in Buka, remarked, 'It is good to see that men are still in control' (reported by an Australian Advisor present at the meeting). Thus it is easy to see why many women do not believe that it is worthwhile to report domestic violence to the police.

18 There is also a third poster, featuring a married couple and a young girl, which addresses the issue of violence against children. This one does not seek to redefine masculinity. 
For a number of years AusAID has sponsored rugby league matches in Port Moresby between the respective Prime Ministers' teams. The first of these took place in 2005 as part of the 30th anniversary celebrations of PNG independence. As the Australian High Commissioner to PNG commented at the reception to welcome the visiting Australian team: 'Sport can bring individuals and communities together to discuss tough issues' (Potts 2006). The High Commissioner echoed the theme of playing by the rules that has been a feature of anti-domestic violence messages in Australia when he remarked: 'One of [the players'] key messages is that violence against women is against the rules. We all need to respect women, stop the violence against them and protect them from the spread of HIV and AIDS-here, in Australia, and internationally' (Potts 2006). ${ }^{19} \mathrm{He}$ also reiterated a key message of some of the National AIDS Council posters about staying safe on and off the field: '[The players] will also discuss the importance of playing by the rules - this includes staying safe on and off the field and respecting other people, especially women' (Potts 2006).

During a visit to a community in Port Moresby while the Australian team was on tour, the coach, Mal Meninga (the former Canberra Raiders player and more recently coach of the Queensland State of Origin team) reminded listeners: 'There can be no rugby league players in the future if this terrible disease isn't stopped now' (AusAID 2006, 19). Elsewhere he is reported as saying: 'HIV and AIDS needs to be tackled in Papua New Guinea and the message needs to reach every village that sexual violence against women is not acceptable and only increases the spread of the disease' (Meninga 2006). Through its aid support project to the National AIDS Council AusAID has also produced and funded posters featuring Meninga and Brad Fittler (Captain of the Sydney Roosters and Captain of Australian Kangaroos Rugby League team). The first poster (see Figure 1) showed Fittler wearing a cap with the slogan Lukautim yu yet AIDS (Protect yourself from AIDS) and featuring the slogan 'Play Safe ... Stay Safe': 'To be World Champions we need to play hard, but we also play it safe. And in life, like sport you have to play safe to stay safe ... from AIDS'. Later posters featured Fittler and Meninga (see Figure 2) more directly promoting the use of condoms, each holding a packet of the socially marketed condoms, Karamap. Again, these put the play safe, play hard message: 'You know life is like sport, you need to play hard, but also play safe in order to stay safe ... from AIDS'. The message concluded by reminding the viewers that if they were thinking about sex to think about using Karamap condoms.

19 An almost identical message was voiced by the next Australian High Commissioner in 2007 (Sydney) Morning Herald, 16 August 2007). 


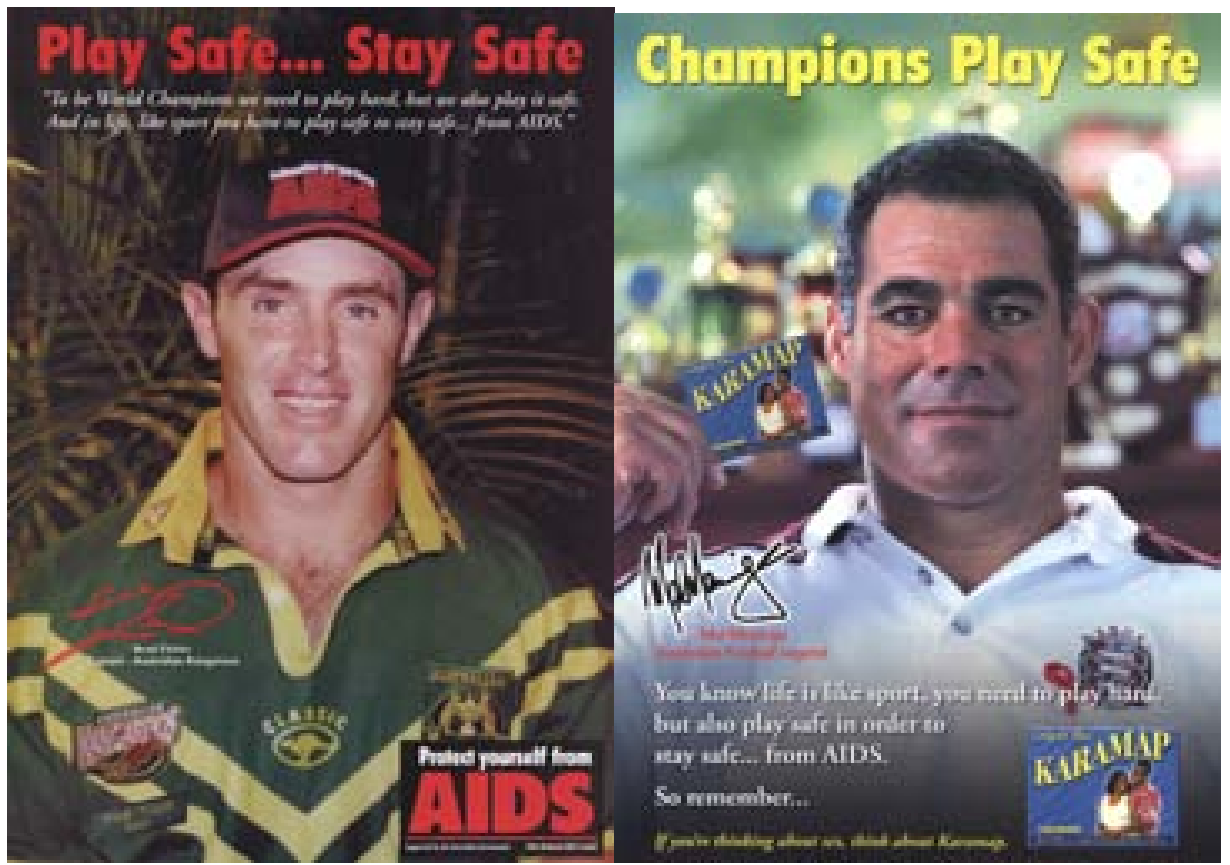

Figure 1 (left): Poster featuring Brad Fittler. PNG National AIDS Council. From the collections of Richard Eves.

Figure 2 (right): Poster featuring Mal Meninga. PNG National AIDS Council. From the collections of Richard Eves.

An effort to rescript masculinity was also made in two early AIDS prevention posters promoting the use of condoms. The first featured a spear-wielding warrior in traditional highlands dress holding a body-sized condom in front of himself instead of a shield. The message on the poster declared that he was not afraid because he has protection (Mi no poret, Mi gat banis). The second poster had an identical message but featured a warrior in coastal dress. Rather than being ready for battle, these warriors were ready for sex. As Campbell has noted, internationally some HIV prevention programs have often considered it 'useful to associate condom use with masculinity, promoting the idea that a man proves his masculinity by using condoms' $(1995,206)$. While this strategy may sometimes be effective, it is based on traditional notions of manliness and reinforces associations between masculinity and strong sexual performance (Campbell 1995, 206; Eves and Butt 2008, 6). Rather than displacing forms of masculinity that encourage violence or predatory sexual behaviour, such approaches encourage the very aspects of masculinity that need to be displaced. This leads Flood to caution against approaches that appeal to men's sense of 'real' manhood or that invite them to 'prove themselves as men', since they may in fact actually intensify men's investment in the status quo. These are even more 
problematic if they represent certain qualities as uniquely male, thus assigning particular qualities such as strength and courage to men and effectively denying them to women (Flood 2002-3, 27).

Posters featuring sporting stars and which emphasise 'playing hard' run into the same problems that Campbell and Flood point out, especially when considering that sport often encourages and values dominant masculine traits, such as extreme competitiveness and aggression. Indeed, one has to look no further than the history of rugby league in PNG, which as one commentator has remarked is a history of violence (Foster 2006, 753). Far from being a 'universal language that can bring people together, no matter what their origin, background, religious beliefs or economic status' (Kofi Annan in AusAID 2006, 15), it can be a divisive force. The expatriate chairman of PNG Rugby League, alluded to this divisiveness when he commented prior to a State of Origin series that, 'it's almost a substitute for rival warfare, or for showing dominance of my clan over your clan' (cited in McLeod 2003).

Violence has often marred the State of Origin series that is so enthusiastically supported in PNG. The celebrations accompanying the watching of the games often degenerate into drunkenness and violence in which people are sometimes killed. ${ }^{20}$ Not only does violence take place in the public settings where the game is watched, but also within homes where husbands and wives fight amongst themselves if they support opposing teams. This has led political leaders to call for the broadcasts to be banned (Foster 2006, 753).

Violence has also marred domestic PNG rugby, with the 2007 premier rugby league competition being suspended due to violence, including a referee being beaten senseless by a supporter. On this 'rugby league disgrace' the editorial writer of The National newspaper wondered what had turned 'team sports into a minefield of blood and potentially deadly confrontations?', commenting that the game is 'regularly transformed into bloody clashes' (The National, 9 May 2007).

\section{Conclusion: Preventing Violence}

The Declaration on the Elimination of all forms of Violence Against Women (DEVAW) calls for states and civil society to develop 'in a comprehensive way, preventive approaches and all those measures of a legal, political, administrative and cultural nature that promote the protection of women against any form of

20 During the colonial period the annual match between Papua and New Guinea, rather than cultivating a sense of national unity, emphasised division, with the 1969 match leading to looting and rioting. Eventually, in 1972 the match was abandoned (Foster 2006, 753). 
violence' (UN General Assembly 1993). Speaking about the worldwide problem of violence towards women, Michau calls for the implementation of a primary prevention approach that focuses on preventing violence before it occurs. This means not only creating a legal and policy environment supportive of women's rights, but fostering a culture which promotes non-violence and relationships based on equity, and supporting individuals to take a public stand against abuse $(2005,3)$. This, says Michau, requires moving beyond programs that focus on one sector (such as health, police, education or judiciary) or one group (such as policy makers, battered women or youth), since effective change requires a critical mass of institutions and people who aspire to these ideals and are prepared to put their beliefs into practice. An essential first step, she argues, is to develop a gender-based analysis of why violence occurs and to recognise that women's low status, the imbalance of power, and rigid gender roles are root causes of violence against women $(2005,3)$.

As I stated at the start of this chapter, the automatically accepted notion that gender equals women has meant that programs to eliminate gender-based violence have concentrated on women as victims or potential victims. Men, meanwhile, have generally been taken for granted as the problem, and excluded from any positive consideration. This problem, then, was addressed mainly in negative terms, particularly the need for greater criminal justice interventions such as restraining orders and prosecution (UNDAW 2005, 30-31). In PNG, for example, most of the solutions recommended by the Law Reform Commission focused on legal changes intended to extend the protection of the law to women (Bradley 2001, 21). While an obvious need does exist for a much stronger law and justice sector approach, gender-based violence is a complex problem which cannot be solved by this alone. This is not merely because much gender-based violence is not brought to the notice of the law and justice sector but because legal and judicial measures do not address the root causes of violence. Those attempts made so far to target men through public education campaigns have also rested on easy assumptions, running the risk of reinscribing the very behaviour that needs to be eliminated, since they fail to interrogate masculinity, often appealing to existing hegemonic masculine ideals. The lesson to learn from this is that there are no simple solutions; all assumptions need to be closely interrogated. Detailed knowledge and skill, solid research and careful thought are needed to produce worthwhile programs.

As I noted at the outset, it is now more widely appreciated that if genderbased violence is to cease and the AIDS epidemic to be contained and reversed, fundamental changes are needed in men's attitudes and beliefs about women and their roles in society. Indeed, it is more and more being argued that efforts to prevent violence against women 'will fail unless they undermine the cultural and collective supports for physical and sexual assault found among many men' 
(Flood 2002-3, 25). Flood and other researchers are saying that an essential way to deal with unequal gender relations and violence against women is to challenge and change dominant models of masculinity (UNDAW 2005, 32). In other words, the relationships between violence, masculinity and gender need to be understood and challenged. Since the problem of violence, and particularly violence by men against women, is clearly a category of gender, then male socialisation and what it means to be a man becomes a central aspect of any solution. It appears that many men see their manhood as dependent on their control over women and they use violence to achieve this. This has obvious ramifications for HIV prevention, as the examples presented in this chapter illustrate.

The role of men and boys in challenging and changing unequal power relations is essential (UNDAW 2005, 3; Barker 2001, 94). If gender-based violence and HIV transmission is to be seriously tackled and eliminated, men and boys must be included in the project, since they are not only part of the problem, they are part of the solution (Flood 2001, 42). In short, the aim must be to inspire men and boys to take responsibility for their actions and to adopt more constructive and cooperative behaviour. Men and boys should be seen as allies and partners who will participate in redefining manhood (Kaufman 2001, 10). In this positive approach, men should not be seen as the problem, or as criminals who should be punished, but as participants in solving the problem (UNDAW 2005, 32). Since not all successful and manly men are aggressive, and many positively reject and condemn violence, it cannot be argued that violence is an essential aspect of the male identity. The rejection of violence by some men clearly suggests that alternative models of masculinity exist and, indeed, in some traditions for a man to strike a woman is considered most unmanly. ${ }^{21}$ This also occurs in PNG where, although violence often constitutes a pervasive manifestation of masculinity, many men are rejecting this in favour of more equitable and nonviolent relationships. The challenge is to find ways of making these alternative masculinities mainstream. ${ }^{22}$

\section{Acknowledgements}

The field research for this chapter was undertaken during a consultancy for Caritas Australia: Exploring the role of men and masculinities in PNG in the 21st century: Finding solutions to address violence that generates empowerment for both men and women. It was written while I was an Australian Research

21 The Bena Bena of the Eastern Highlands have an expression which means that if a man beats his wife her blood will cover him up, he will not be able to see and will behave like an animal (pers. comm. Naomi Yupae). 22 The Caritas report suggests many practical initiatives to encourage alternative, more cooperative ways of men relating to women as equal partners (Eves 2006). 
Civic Insecurity

Council QE II Research Fellow in the State Society and Governance in Melanesia Program and I thank SSGM and the ARC for their institutional and funding support. The piece has benefited greatly from the constructive comments and editorial suggestions of Roe Sybylla.

\section{References}

Aeno, H. 2005. Marriage, Sex and STDs: Transmission Risks of Papua New Guinean Women as Assessed Through HIVab Counselling. Paper presented at the Annual Meeting of the Association for Social Anthropology in Oceania, Kauai, Hawai'i, February 2-6.

AI (Amnesty International). 2006. Papua New Guinea Violence Against Women: Not Inevitable, Never Acceptable! AI Index: ASA 34/002/2006.

Anon. 2007. Fittler, Meninga to Coach PM's XIII. Sydney Morning Herald, 16 August, 2007. http://www.smh.com.au/news/Sport/Fittler-Meninga-tocoach-PMs-XIII/2007/08/16/1186857670449.html (accessed 27 April 2010).

AusAID. 2006. Playing the Game. Focus Jan.-April 2006: 15-19. Canberra: AusAID.

Australian Government. 2008. Media Release: Australian Support for PNG. 7 March 2008.

Banks, C. 2000. Contextualising Sexual Violence: Rape and Carnal Knowledge in Papua New Guinea. In Reflections on Violence in Melanesia, ed. S. Dinnen and A. Ley, 83-104. Leichhardt and Canberra: Hawkins Press (Federation Press) and Asia Pacific Press.

Barker, G. 2001. 'Cool Your Head, Man': Preventing Gender Based Violence in Favelas. Development 44 (3): 94-98.

Barker, G. and C. Ricardo. 2005. Young Men and the Construction of Masculinity in Sub-Saharan Africa: Implications for HIV/AIDS, Conflict, and Violence. World Bank Social Development Papers: Conflict Prevention and Reconstruction, No. 26. Washington: World Bank.

Beer, B. 2008. Buying Betel and Selling Sex: Contested Boundaries, Risk Milieus, and Discourses about HIV/AIDS in the Markham Valley, Papua New Guinea. In Making Sense of AIDS: Culture, Sexuality, and Power in Melanesia, ed. L. Butt and R. Eves, 97-115. Honolulu: University of Hawai'i Press. 
Bradley, C. 1985. Attitudes and Practices Relating to Marital Violence among the Tolai of East New Britain. In Domestic Violence in Papua New Guinea, ed. S. Toft, 33-71. Law Reform Commission of Papua New Guinea Monograph No. 3. Port Moresby: Law Reform Commission of Papua New Guinea.

Bradley, C. 2001. Family and Sexual Violence in PNG: An Integrated Long-Term Strategy. Report to the Family Violence Action Committee of the Consultative Implementation and Monitoring Council. Discussion Paper No. 84. Port Moresby: Institute of National Affairs.

Brison, K. 1995. Changing Constructions of Masculinity in a Sepik Society. Ethnology 34 (3): 155-175.

Brown, P. 1988. Gender and Social Change: New Forms of Independence for Simbu Women. Oceania 59 (2): 123-142.

Brown, J., J. Sorrell and M. Raffaelli. 2005. An Exploratory Study of Constructions of Masculinity, Sexuality and HIV/AIDS in Namibia, Southern Africa. Culture, Health and Sexuality 7 (6): 585-598.

Bujra, J. 2000. Risk and Trust: Unsafe Sex, Gender and AIDS in Tanzania. In Risk Revisited, ed. P. Caplan, 59-84. London: Pluto Press.

Campbell, C. 1992. Learning to Kill? Masculinity, the Family and Violence in Natal. Journal of Southern African Studies 18 (3): 614-628.

Campbell, C. 1997. Migrancy, Masculine Identities, and AIDS: The Psychosocial Context of HIV Transmission on the South African Gold Mines. Social Science and Medicine 45 (2): 273-281.

Campbell, C. A. 1995. Male Gender Roles and Sexuality: Implications for Women's AIDS Risk and Prevention. Social Science and Medicine 41 (2): 197210 .

Carovano, K. 1995. HIV and the Challenges Facing Men. Issues Paper No. 15. UNDP: HIV and Development Programme.

Chege, J. 2005. Interventions Linking Gender Relations and Violence with Reproductive Health and HIV: Rationale, Effectiveness and Gaps. Agenda: Special Focus on Gender, Culture and Rights (special issue): 114-123.

Cleaver, F. 2002. Men and Masculinities: New Directions in Gender and Development. In Making Men Matter: Men, Masculinities and Gender Relations in Development, ed. F. Cleaver, 1-27. London: Zed Books.

Connell, R. W. 1995. Masculinities. Berkeley: University of California Press. 
Cornwall, A. and N. Lindisfarne. 1994. Introduction. In Dislocating Masculinity: Comparative Ethnographies, ed. A. Cornwall and N. Lindisfarne, 1-10. London: Routledge.

Courtenay, W. H. 2000. Constructions of Masculinity and their Influence on Men's Well-Being: A Theory of Gender and Health. Social Science and Medicine 50 (10): 1385-1401.

Dowsett, G. W., P. Aggleton, S. Abega, C. Jenkins, T. M. Marshall, A. Runganga, J. Schifter, M. L. Tan, and C. M. Tarr. 1998. Changing Gender Relations among Young People: The Global Challenge for HIV/AIDS Prevention. Critical Public Health 8 (4): 291-309.

Dunkle, K. L., R. K. Jewkes, H. C. Brown, M. Yoshihama, G. E. Gray, J. A. McIntyre and S. D. Ha. 2004. Prevalence and Patterns of Gender-based Violence and Revictimization among Women Attending Antenatal Clinics in Soweto, South Africa. American Journal of Epidemiology 160 (3): 230-239.

Ellison, G. T. H., with M. Parker and C. Campbell. 2003. Introduction: Learning from HIV and AIDS: From Multidisciplinary to Interdisciplinarity. In Learning from HIV and AIDS, ed. G. Ellison, M. Parker and C. Campbell, 1-31. Cambridge: Cambridge University Press.

Eves, R. 2006. Exploring the Role of Men and Masculinities in Papua New Guinea in the 21st century: How to Address Violence in Ways that Generate Empowerment for Both Men and Women. Sydney: Caritas Australia.

Eves, R. and L. Butt. 2008. Introduction. In Making Sense of AIDS: Culture, Sexuality, and Power in Melanesia, ed. L. Butt and R. Eves, 1-23. Honolulu: University of Hawai'i Press.

Flood, M. 2001. Men's Collective Anti-Violence Activism and the Struggle for Gender Justice. Development 44 (3): 42-47.

Flood, M. 2002-3. Engaging Men: Strategies and Dilemmas in Violence Prevention Education among Men. Women Against Violence: A Feminist Journal 13: 25-32.

Foreman, M., ed. 1999. AIDS and Men: Taking Risks or Taking Responsibility? London: The Panos Institute and Zed Books.

Foster, R. J. 2006. From Trobriand Cricket to Rugby Nation: The Mission of Sport in Papua New Guinea. The International Journal of the History of Sport 23 (5): 739-758.

Giffin, K. 1998. Beyond Empowerment: Heterosexualities and the Prevention of AIDS. Social Science and Medicine 46 (2): 151-156. 
Global Coalition on Women and AIDS and WHO 2004. Violence Against Women and HIV/AIDS: Critical Intersections - Intimate Partner Violence and HIV/ AIDS. Information Bulletin Series No. 1. Geneva: WHO.

Goddard, M. 2004. Women in Papua New Guinea's Village Courts. State, Society and Governance in Melanesia Discussion Paper 2004/3. Canberra: State, Society and Governance in Melanesia (SSGM), Research School of Pacific and Asian Studies, Australian National University.

Gupta, G. R. 1995. Integrating a Gender Perspective in UNAIDS Policies and Programmes: A Proposed Strategy. Geneva: UNAIDS.

Gupta, G. R. and E. Weiss. 1993. Women's Lives and Sex: Implications for AIDS prevention. Culture, Medicine and Psychiatry 17 (4): 399-412.

Haley, N. 2005. PNG Armed Violence Assessment. Port Moresby: UNDP.

Haley, N. 2008. When There's No Accessing Basic Health Care: Local Politics and Responses to HIV/AIDS at Lake Kopiago, Papua New Guinea. In Making Sense of AIDS: Culture, Sexuality, and Power in Melanesia, ed. L. Butt and R. Eves, 24-40. Honolulu: University of Hawai'i Press.

Haley, N. and R. Muggah. 2006. Jumping the Gun: Armed Violence in Papua New Guinea. In Small Arms Survey 2006, 165-187. Oxford: Oxford University Press.

Harrison, A., L. F. O'Sullivan, S. Hoffman, C. Dolezal and R. Morrell. 2006. Gender Role and Relationship Norms among Young Adults in South Africa: Measuring the Context of Masculinity and HIV Risk. Journal of Urban Health 83 (4): 709-722.

Heise, L. L. and C. Elias. 1995. Transforming AIDS Prevention to Meet Women's Needs: A Focus on Developing Countries. Social Science and Medicine 40 (7): 931-943.

HELP Resources. 2005. A Situational Analysis of Child Sexual Abuse and the Commercial Sexual Exploitation of Children in Papua New Guinea. Port Moresby, PNG: HELP Resources, Inc. with the support of UNICEF PNG.

Herdt, G. H. 1981. Guardians of the Flutes: Idioms of Masculinity. New York: McGraw Hill.

Herdt, G. H., ed. 1992. Rituals of Manhood: Male Initiation in Papua New Guinea. Berkeley: University of California Press. 
Civic Insecurity

HRW (Human Rights Watch). 2005. 'Making their Own Rules': Police Beatings, Rape, and Torture of Children in Papua New Guinea. New York: Human Rights Watch.

HRW (Human Rights Watch). 2006. Still Making their Own Rules: Ongoing Impunity for Police Beatings, Rape, and Torture in Papua New Guinea. New York: Human Rights Watch.

Hunter, M. 2005. Cultural Politics and Masculinities: Multiple-Partners in Historical Perspective in KwaZulu-Natal. Culture, Health and Sexuality 7 (4): 389-403.

INA (Institute of National Affairs). 2001. A Life Free From Violence-It's Our Right. Proceedings of the Family Violence Workshop 13 and 14 September 2000. Port Moresby: Institute of National Affairs.

Jewkes, R. K., J. B. Levin and L. A. Penn-Kekana. 2003. Gender Inequalities, Intimate Partner Violence and HIV Preventive Practices: Findings of a South African Cross-Sectional Study. Social Science andMedicine 56 (1): 125-134.

Johnson, F. C. 2001. Strategies to End Gender Based Violence: The USAID Approach. Development 44 (3): 125-128.

Josephides, L. 1985. The Politics of Violence in Kewa Society (Southern Highlands). In Domestic Violence in Papua New Guinea, ed. S. Toft, Law Reform Commission of Papua New Guinea Monograph No. 3, 92-103. Port Moresby: Law Reform Commission of Papua New Guinea.

Josephides, L. 1994. Gendered Violence in a Changing Society: The Case of Urban Papua New Guinea. Journal de la Société des Océanistes 99: 187-196.

Kaler, A. 2003. 'My Girlfriends Could Fill A Yanu-Yanu Bus': Rural Malawian Men's Claims About Their Own Serostatus. Demographic Research, Special Collection 1: 350-372.

Kaufman, M. 2001. Building a Movement of Men Working to End Violence Against Women. Development 44 (3): 9-14.

Larkin, J., A. Andrews and C. Mitchell. 2006. Guy Talk: Contesting Masculinities in HIV Prevention Education with Canadian Youth. Sex Education 6 (3): 207221.

Lewis, I., B. Maruia, D. Mills and S. Walker. 2007. Final Report on Links Between Violence Against Women and the Transmission of HIV in PNG. Port Moresby: National AIDS Council. 
Liguori, A. L. and M. Lamas. 2003. Commentary: Gender, Sexual Citizenship and HIV/AIDS. Culture, Health and Sexuality 5 (1): 87-90.

Luluaki, J. Y. 2003. Sexual Crimes Against and Exploitation of Children and the Law in Papua New Guinea. International Journal of Law, Policy and the Family 17 (3): 275-307.

LRC (Law Reform Commission). 1987. Interim Report. Port Moresby: Papua New Guinea Law Reform Commission.

LRC (Law Reform Commission). 1992. Final Report on Domestic Violence. Report No. 14. Port Moresby: Papua New Guinea Law Reform Commission.

Maman, S., J. Campbell, M. D. Sweat and A. C. Gielen. 2000. The Intersections of HIV and Violence: Directions for Future Research and Interventions. Social Science and Medicine 50 (4): 459-478.

Mane, P. and P. Aggleton. 2001. Gender and HIV/AIDS: What Do Men Have to Do with It? Current Sociology 49 (6): 23-37.

McDowell, N. 1990. Person, Assertion, and Marriage: On the Nature of Household Violence in Bun. Pacific Studies 13 (3): 171-188.

McLeod, A. 2005. Violence, Women and the State in Papua New Guinea: A Case Note. Development Bulletin 67: 115-118.

McLeod, S. 2003. Papua New Guinea Falls Victim to State of Origin Fever, 11 June 2003. http://www.abc.net.au/pm/content/2003/s877613.htm (accessed 27 April 2010).

Medrado, B. 2003. Men, Masculinities and Gender Violence. United Nations Division for the Advancement of Women (DAW) in Collaboration with International Labour Organization (ILO) Joint United Nations Programmes on HIV/AIDS (UNAIDS) United Nations Development Programme (UNDP) Expert Group Meeting on 'The Role of Men and Boys in Achieving Gender Equality', 21-24 October 2003, Brasilia, Brazil.

Meninga, M. 2006. Big Mal and Boys Land in Cairns. The World of Rugby League, Rleague Grandstand Forumshttp://forums.rleague.com/showthread. php?t=19470 (accessed 27 April 2010).

Michau, L. 2005. Good Practice in Designing a Community-Based Approach to Prevent Domestic Violence. Paper at the Expert Group Meeting Workshop 'Violence Against women: Good Practices in Combating and Eliminating Violence Against Women', Organized by UN Division for the Advancement of Women, May 2005, Vienna, Austria. 
Civic Insecurity

Nash, J. 1990. Factors Relating to Infrequent Domestic Violence among the Nagovisi. Pacific Studies 13 (3): 127-140.

Nduwimana, F. 2004. The Right to Survive: Sexual Violence, Women and HIV/ AIDS. Montreal: International Centre for Human Rights and Democratic Development.

NRI (National Research Institute) and JAG (Justice Advisory Group). 2005. Port Moresby Community Crime Survey, 2004. Waigani: National Research Institute.

NSRRT (National Sex and Reproduction Research Team) and C. Jenkins. 1994. National Study of Sexual and Reproductive Knowledge and Behaviour in Papua New Guinea. Monograph No. 10. Goroka: Papua New Guinea Institute of Medical Research.

PNG NAC (Papua New Guinea National AIDS Council). 2006a. Papua New Guinea National Strategic Plan on HIV/AIDS 2006-2010. Port Moresby: National AIDS Council.

PNG NAC. 2006b. National Gender Policy and Plan on HIV and AIDS 20062010. Port Moresby: National AIDS Council.

PNG NACS (Papua New Guinea National AIDS Council Secretariat) and Partners. 2008. UNGASS 2008 Country Progress Report. Papua New Guinea Reporting Period: January 2006-December 2007. http://data.unaids.org/pub/ Report/2008/papua_new_guinea_2008_country_progress_report_en.pdf (accessed 27 April 2010).

Potts, M. 2006. Speech at the Australian High Commissioner's Reception for the Visiting Prime Minister's XIII Australian Rugby League Team. 28 September 2006. http://www.png.embassy.gov.au/pmsb/PMXIII.html (accessed 27 April 2010).

Read, K. 1982. Male-Female Relationships among the Gahuku-Gama: 1950 and 1981. Social Analysis 12: 66-78.

Rivers, K. and P. Aggleton. 1999. Men and the HIV Epidemic, Gender and the HIV Epidemic. New York: UNDP HIV and Development Programme.

Rothenberg, K. H. and S. J. Paskey. 1995. The Risk of Domestic Violence and Women with HIV Infection: Implications for Partner Notification, Public Policy, and the Law. American Journal of Public Health 85 (11): 1569-1576.

Scaglion, R. 1990. Spare the Rod and Spoil the Woman? Family Violence in Abelam Society. Pacific Studies 13 (3): 189-204. 
Scheper-Hughes, N. 1994. An Essay: AIDS and the Social Body. Social Science and Medicine 39 (7): 991-1003.

Seidel, G. and L. Vidal. 1997. The Implications of 'Medical', 'Gender in Development' and 'Culturalist' Discourses for HIV/AIDS Policy in Africa. In Anthropology of Policy: Critical Perspectives on Governance and Power, ed. C. Shore and S. Wright, 59-87. London: Routledge.

Setel, P. 1996. AIDS as a Paradox of Manhood and Development in Kilimanjaro, Tanzania. Social Science and Medicine 43 (8): 1169-1178.

Toft, S. 1985. Marital Violence in Port Moresby: Two Urban Case studies. In Domestic Violence in Papua New Guinea. Law Reform Commission of Papua New Guinea Monograph No. 3, ed. Susan Toft, 14-31. Port Moresby: Law Reform Commission of Papua New Guinea.

Toft, S. and S. Bonnell. 1985. Marriage and Domestic Violence in Rural Papua New Guinea. Occasional Paper No. 18. Waigani: Law Reform Commission.

UN (United Nations). 2006. Report of the Secretary-General In-Depth Study on all Forms of Violence Against Women. Sixty-First Session. Advancement of Women: Advancement of Women A/61/122/Add.1. New York: United Nations.

UNAIDS (Joint United Nations Programme on HIV/AIDS). 1999. Gender and HIV/AIDS: Taking Stock of Research and Programmes. Geneva: UNAIDS.

UNAIDS. 2000a. Gender and AIDS Almanac. Geneva: UNAIDS.

UNAIDS. 2000b. Men Make A Difference: Objectives and Ideas for Action. Geneva: UNAIDS.

UNAIDS. 2000c. Men and AIDS - a Gendered Approach: 2000 World AIDS Campaign. Geneva: UNAIDS.

UNAIDS. 2001. Working with Men for HIV Prevention and Care. Geneva: UNAIDS.

UNAIDS and KIT (Royal Tropical Institute). 2005. Operational Guide on Gender and HIV/AIDS: A Rights-Based Approach. Amsterdam: UNAIDS InterAgency Task Team on Gender and HIV/AIDS, KIT Publishers.

UNAIDS/The Panos Institute. 2001. Young Men and HIV: Culture, Poverty and Sexual Risk. Geneva and London: UNAIDS/The Panos Institute. 
Civic Insecurity

UNAIDS, UNFPA (United Nations Population Fund) and UNIFEM (United Nations Development Fund for Women). 2004. Women and HIV/AIDS: Confronting the Crisis. New York: UNAIDS/UNFPA/UNIFEM.

UNDAW (UN Division for the Advancement of Women). 2000. The HIV/AIDS Pandemic and its Gender Implications. Report of the Expert Group Meeting Windhoek, Namibia, 13-17 November 2000. New York: Division for the Advancement of Women.

UNDAW in collaboration with Economic Commission for Europe (ECE) and World Health Organization (WHO). 2005. Violence Against Women: A Statistical Overview, Challenges and Gaps in Data Collection and Methodology and Approaches for Overcoming Them. Report of the Expert Group Meeting Geneva, Switzerland, 11-14 April 2005.

UNDAW. 2004. The Role of Men and Boys in Achieving Gender Equality. Report of the Expert Group Meeting Brasilia, Brazil, 21-24 October 2003, Final Report. New York: UNDAW.

UNDP (United Nations Development Programme). 2005. A Gender Audit of the National Strategic Plan on HIV/AIDS 2006-2010. Port Moresby: United Nations Development Programme.

UNFPA. 2000. Partners for Change: Enlisting Men in HIV/AIDS Prevention. New York: UNFPA.

UNFPA, UNIFEM and OSAGI (Office of the Special Adviser on Gender Issues and Advancement of Women). 2005. Combating Gender-Based Violence: A Key to Achieving the MDGS. New York: UNFPA, UNIFEM and OSAGI.

UN General Assembly. 1993. Declaration on the Elimination of Violence Against Women (DEVAW). UN General Assembly Resolution 48/104.

UN HABITAT and UNDP. 2004. Port Moresby Diagnosis of Insecurity Report. Port Moresby: UN HABITAT and UNDP.

Walsh, S. and C. Mitchell. 2006. 'I'm Too Young to Die': HIV, Masculinity, Danger and Desire in Urban South Africa. Gender and Development 14 (1): 57-68.

Wardlow, H. 2004. Anger, Economy, and Female Agency: Problematizing 'Prostitution' and 'Sex Work' among the Huli of Papua New Guinea. Signs:Journal of Women in Culture and Society 29 (4): 1017-1040.

Wardlow, H. 2006. Wayward Women: Sexuality and Agency in a New Guinea Society. Berkeley: University of California Press. 
Wardlow, H. 2007. Men's Extramarital Sexuality in Rural Papua New Guinea. American Journal of Public Health 97 (6): 1006-1014.

Wardlow, H. 2008. 'You Have to Understand: Some of Us Are Glad AIDS Has Arrived': Christianity and Condoms among the Huli, Papua New Guinea. In Making Sense of AIDS: Culture, Sexuality, and Power in Melanesia, ed. L. Butt and R. Eves, 187-205. Honolulu: University of Hawai'i Press.

WHO (World Health Organization). 2001. Violence Against Women and HIV/ AIDS: Setting The Research Agenda. Geneva: WHO.

WHO. 2003. Integrating Gender into HIV/AIDS Programmes. A Review Paper. Department of Gender and Women's Health Family and Community Health. Geneva: World Health Organization.

WHO. 2004. Gender Dimensions of HIV Status Disclosure to Sexual Partners: Rates, Barriers and Outcomes. A Review Paper. Geneva: WHO.

Wilde, C. 2003. Men at Work: Masculinity, Mutability, and Mimesis among the Gogodala of Papua New Guinea. Ph.D. Thesis, University of Sydney.

Wilde, C. 2007. 'Turning Sex into a Game': Gogodala Men's Response to the AIDS Epidemic and Condom Promotion in Rural Papua New Guinea. Oceania 77 (1): 58-71.

Wood, K. and R. Jewkes. 1997. Violence, Rape, and Sexual Coercion: Everyday Love in a South African Township. Gender and Development 5 (2): 41-46.

Wood, K., F. Marforah and R. Jewkes. 1998. 'He Forced Me to Love Him': Putting Violence on Adolescent Sexual Health Agendas. Social Science and Medicine 47 (2): 233-242.

Zimmer-Tamakoshi, L. 1997. 'Wild Pigs and Dog Men': Rape and Domestic Violence as 'Women's Issues' in Papua New Guinea. In Gender in CrossCultural Perspective, ed. C. Brettell and C. Sargent, 538-553. Englewood Cliffs: Prentice-Hall. 